\section{Nasal high flow oxygen therapy in patients with COPD reduces respiratory rate and tissue carbon dioxide while increasing tidal and end-expiratory lung volumes: a randomised crossover trial}

\begin{abstract}
Patients with COPD using long-term oxygen therapy (LTOT) over $15 \mathrm{~h}$ per day have improved outcomes. As inhalation of dry cold gas is detrimental to mucociliary clearance, humidified nasal high flow (NHF) oxygen may reduce frequency of exacerbations, while improving lung function and quality of life in this cohort. In this randomised crossover study, we assessed short-term physiological responses to NHF therapy in 30 males chronically treated with LTOT. LTOT (2-4 L/min) through nasal cannula was compared with NHF at $30 \mathrm{~L} / \mathrm{min}$ from an AIRVO through an Optiflow nasal interface with entrained supplemental oxygen. Comparing NHF with LTOT: transcutaneous carbon dioxide $\left(\mathrm{TCCO}_{2}\right)$ (43.3 vs $46.7 \mathrm{~mm} \mathrm{Hg}$, $\mathrm{p}<0.001)$, transcutaneous oxygen $\left(\mathrm{TCO}_{2}\right)(97.1$ vs $101.2 \mathrm{~mm} \mathrm{Hg}, p=0.01)$, I:E ratio (0.75 vs $0.86, p=0.02)$ and respiratory rate (RR) (15.4 vs 19.2 bpm, $p<0.001)$ were lower; and tidal volume (Vt) (0.50 vs $0.40, p=0.003)$ and endexpiratory lung volume (EELV) (174\% vs $113 \%$, $p<0.001)$ were higher. EELV is expressed as relative change from baseline $(\% \Delta)$. Subjective dyspnoea and interface comfort favoured LTOT. $\mathrm{NHF}$ decreased $\mathrm{TCCO}_{2}$, l:E ratio and $\mathrm{RR}$, with a concurrent increase in EELV and Vt compared with LTOT. This demonstrates a potential mechanistic rationale behind the improved outcomes observed in long-term treatment with NHF in oxygen-dependent patients.
\end{abstract}

Trial registration number

ACTRN12613000028707.

\section{INTRODUCTION}

The burden of COPD is increasing globally, and its physiological, economical and mortality costs are enormous, with $>65$ million people affected by moderate-to-severe COPD.

Long-term oxygen therapy (LTOT) improves health outcomes and reduces mortality. ${ }^{1}$ However, further optimisation of respiratory support may diminish symptomatic breathlessness, ameliorate COPD-associated cachexia, reduce hypercarbia, improve right ventricular function and provide psychological benefits.

Nasal high flow (NHF) oxygen, an emerging therapy developed for acute care areas for respiratory support, may have the potential for domiciliary use. NHF delivers heated and humidified air/ oxygen with flows up to $60 \mathrm{~L} / \mathrm{min}$. NHF produces pharyngeal pressures of $2-8 \mathrm{~cm}$ $\mathrm{H}_{2} \mathrm{O}^{2}$, which transmit to the alveoli, contributing to lung recruitment and upper airway splinting. ${ }^{3}$ Nasopharyngeal dead space washout has been proposed to reduce $\mathrm{CO}_{2}$ rebreathing, thus providing a fresh reservoir of oxygen from which to breathe. ${ }^{4}$ The observed clinical effects of high gas flows in patients with COPD include improvements in exercise tolerance, oxygenation and reduced dyspnoea. ${ }^{6}$ NHF has been demonstrated to increase tidal volumes in a number of cohorts, ${ }^{7}$ while reducing work of breathing by lowering inspiratory resistance and generating positive expiratory pressure. ${ }^{5}$ NHF has been shown to be non-inferior to non-invasive ventilation in the prevention of treatment failure in patients with acute respiratory failure postcardiac surgery $^{8}$ and reduce mortality (both in the intensive care unit and at 90 days) in patients with acute respiratory failure.

A randomised crossover study was commenced to assess the short-term physiological effects of NHF oxygen in patients with chronic stable COPD.

\section{METHODS}

The online repository for this research letter contains details on study inclusion and exclusion criteria, study procedures and statistical analysis.

\section{Study protocol}

A randomised crossover design was used to study subjects on their own LTOT (low flow oxygen, 2-4 L/min through nasal cannula) and NHF using air supplemented with the equivalent fraction of inspired oxygen $\left(\mathrm{FiO}_{2}\right)$ to a total flow of $30 \mathrm{~L} / \mathrm{min}$ from an AIRVO through an Optiflow nasal interface (Fisher \& Paykel Healthcare, Auckland, New Zealand). Data collected included transcutaneous oxygen $\left(\mathrm{TcO}_{2}\right)$ and transcutaneous carbon dioxide $\left(\mathrm{TcCO}_{2}\right)$; pulse oximetry; tidal volume $(\mathrm{Vt})$ and minute volume $(\mathrm{MV})$, respiratory rate $(\mathrm{RR})$ and I:E ratio via respiratory inductance plethysmography; end-expiratory lung impedance (EELI) via electrical impedance tomography; heart rate (HR) via standard ECG monitoring; subjective dyspnoea and comfort scores $(0=$ no dyspnoea/discomfort to $10=$ maximum dyspnoea/discomfort); and videography of the patients' torso to identify inconsistencies during data analysis such as coughing and sneezing.

Patients remained on LTOT during the $20 \mathrm{~min}$ set-up period while baseline recordings were taken. Patients received the first randomised therapy (LTOT or NHF) for $20 \mathrm{~min}$, followed by a $20 \mathrm{~min}$ washout period of LTOT, after which they crossed over to the second therapy (LTOT or NHF) for $20 \mathrm{~min}$.

\section{RESULTS}

Details regarding the numbers of patients screened and subsequently excluded are contained in the online repository. Thirty patients were included in the study (see tables in online repository for patient characteristics). Results are contained in table 1.

When comparing NHF with LTOT, $\mathrm{TcO}_{2}, \mathrm{TcCO}_{2}, \mathrm{RR}$ and I:E ratio were significantly lower when using NHF. On NHF, $\mathrm{Vt}$ and EELI were significantly higher than on LTOT. Figure 1 illustrates the decrease in $\mathrm{TcCO}_{2}$ and RR. No significant difference between groups was found in $\mathrm{SpO}_{2}, \mathrm{MV}$ or $\mathrm{HR}$.
Table 1 Two-way (paired) comparisons between the long-term oxygen therapy (LTOT) and nasal high flow (NHF) groups

\begin{tabular}{lllr}
\hline Variable & LTOT & NHF & p Value \\
\hline Oxygen saturation $(\%)^{*}$ & $95.8(94.6$ to 96.9$)$ & $95.7(93.1$ to 97.1$)$ & 0.06 \\
Transcutaneous $\mathrm{O}_{2}(\mathrm{~mm} \mathrm{Hg})$ & $101.2(22.5)$ & $97.1(24.2)$ & 0.01 \\
Transcutaneous $\mathrm{CO}_{2}(\mathrm{~mm} \mathrm{Hg})$ & $46.7(9.4)$ & $43.3(9.5)$ & $<0.001$ \\
Respiratory rate (breaths/min) & $19.2(6.3)$ & $15.4(4.8)$ & 0.001 \\
Inspiratory:expiratory ratio & $0.86(0.20)$ & $0.75(0.25)$ & 0.02 \\
Tidal volume $(\mathrm{L})^{*}$ & $0.40(0.34,0.46)$ & $0.50(0.41,0.54)$ & 0.003 \\
Minute volume $(\mathrm{L} / \mathrm{min})^{*}$ & $6.20(4.84,8.18)$ & $6.18(4.75,7.69)$ & 0.88 \\
Heart rate (beats/min) & $70.1(59.1,79.3)$ & $69.8(61.3,79.8)$ & 0.21 \\
End-expiratory lung impedance $(\% \Delta)^{*}$ & $113(98,128)$ & $174(161,187)$ & $<0.001$
\end{tabular}

A p value $<0.05$ was considered significant. Normally distributed data are presented as mean (SD) while non-normal data are presented as median (IQR). End-expiratory lung impedance data are presented as percentage change from baseline $(\% \Delta)$. All variables returned to baseline values during the washout periods and subsequently during the recovery period.

*A paired $t$ test was used for the normally distributed data while a Wilcoxon signed rank test was used for the non-normal data. 

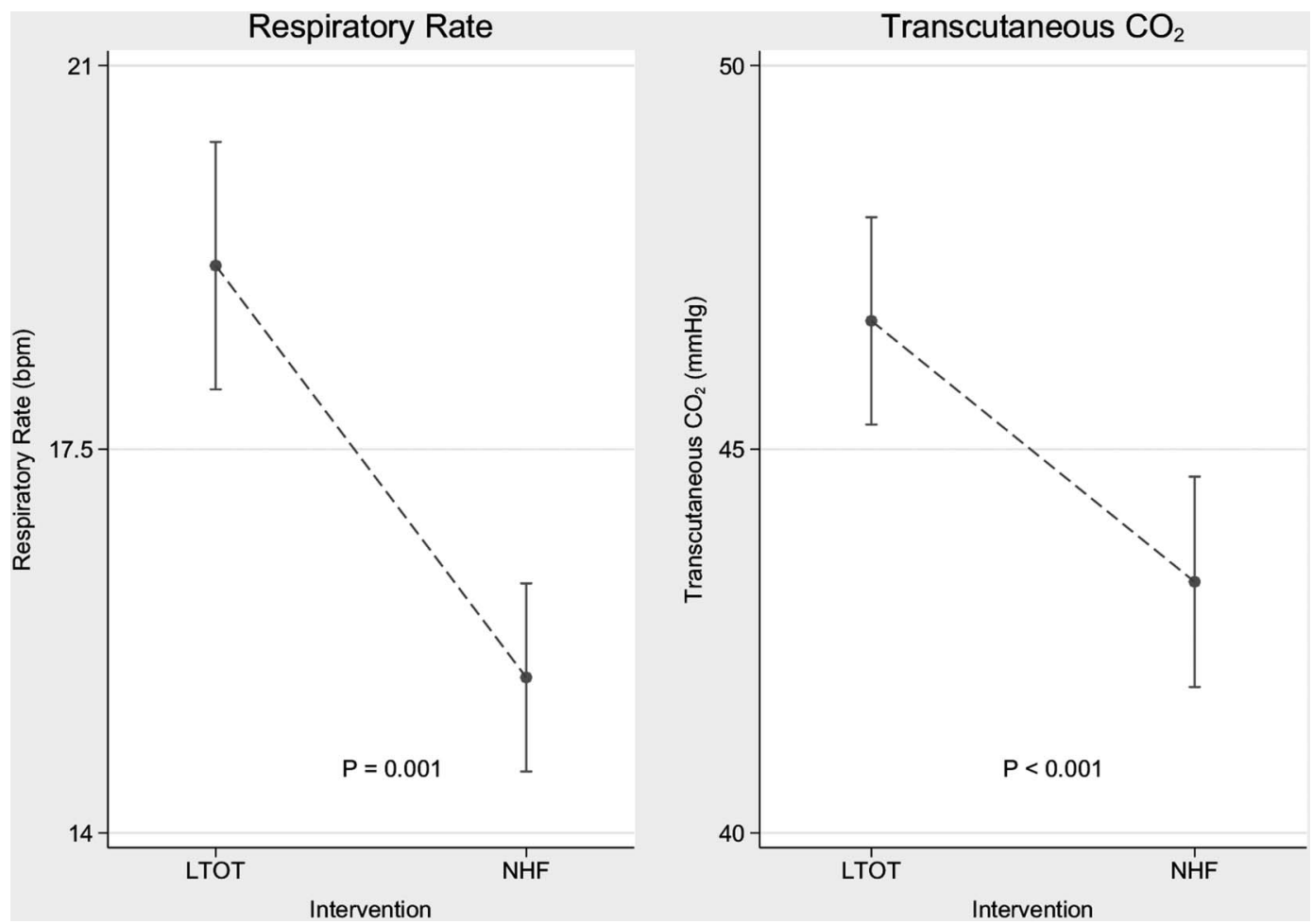

Figure 1 Observed decreases in respiratory rate and transcutaneous carbon dioxide level between the long-term oxygen therapy (LTOT) group and the nasal high flow (NHF) group. Data are presented as mean and vertical 95\% Cl bars.

Median subjective dyspnoea scores were significantly higher during NHF compared with LTOT (LTOT: median 0.5 [range 0-3.5]; NHF: $\left.2.00-^{5}, \mathrm{p}<0.001\right)$. Similarly with interface comfort, LTOT was more comfortable than NHF (LTOT: $9 ;^{7-10}$ NHF: $\left.8[2.5-10], p<0.02\right)$.

\section{DISCUSSION}

In this study, NHF in patients with stable oxygen-dependent COPD led to a significant reduction in $\mathrm{TcCO}_{2}$ levels. NHF use also resulted in increases in $\mathrm{Vt}$, endexpiratory lung volume (EELV) and I:E ratio with corresponding decreases in $\mathrm{RR}$, without changes to MV. These short-term findings, if confirmed over a longer duration in subsequent studies, could imply a role for NHF in the domiciliary management of patients with COPD dependent on LTOT.

Hypercarbia, respiratory acidosis and failure are all associated with increased risk of acute deterioration and poor outcomes for patients with COPD. Home NHF use with titrated or low-level supplemental oxygen may assist in avoiding these problems. How long patients should be maintained on this strategy for the benefits of NHF to be sustained is unclear; however, in a recent study of long-term domiciliary use of NHF, the actual exposure time to NHF was $1.6 \mathrm{~h} /$ day. ${ }^{10}$ The supplemental benefit of reduced $\mathrm{TcCO}_{2}$, reduced RR and increased EELV and Vt, combined with adequate oxygen to prevent hypoxia and pulmonary hypertension, is unknown, indicating the need for a long-term study in the domiciliary setting. This reduction in $\mathrm{TcCO}_{2}$ correlates with the consistent rise in $\mathrm{Vt}$, and we believe this increase may be accompanied by dead space and subsequent $\mathrm{CO}_{2}$ washout, as seen in preceding COPD studies. ${ }^{6}$

The ability of NHF to reduce RR is consistent with a reduction in work of breathing. The mechanism is most likely the reduced anatomical dead space assisted by the positive expiratory pressure effect of NHF, which allows for improved ventilation and perfusion matching. Additionally, matching the inspiratory flow demands with NHF overcomes nasopharyngeal inspiratory resistance, thereby diminishing resistive work of breathing. ${ }^{5}$

In this NHF-naive cohort, higher dyspnoea and lower comfort scores were observed during NHF, perhaps due to commencing a new treatment in a cohort known to suffer from anxiety.

This study has some limitations that are contained in the online repository.

\section{CONCLUSIONS}

This study demonstrates that in the stable home-oxygen-dependent male COPD patient, short-term NHF use results in reductions in $\mathrm{TcCO}_{2}$ and $\mathrm{RR}$, with increased Vt and EELV, when compared to LTOT. However, this cohort rated their LTOT interface more comfortable and providing more dyspnoea relief than NHF. This short-term study demonstrates adequate physiological rationale to proceed with trialling these devices in the long-term management of COPD, with the hope of reducing further physiological decay, improving quality of life and reducing hospital admissions.

\section{John F Fraser, ${ }^{1}$ Amy J Spooner, ${ }^{1}$ Kimble R Dunster, ${ }^{1,2}$ Chris M Anstey, ${ }^{1,3}$ Amanda Corley ${ }^{1}$}

${ }^{1}$ Critical Care Research Group, The Prince Charles Hospital and University of Queensland, Brisbane, Australia

${ }^{2}$ Biomedical Engineering and Medical Physics, Science and Engineering Faculty, Queensland University of Technology, Brisbane, Australia

${ }^{3}$ Intensive Care Unit, Nambour General Hospital, Nambour, Australia

Correspondence to Amanda Corley, Critical Care Research Group, Level 5 CSB, The Prince Charles Hospital, Rode Rd, Chermside, Brisbane, QLD 4032, Australia; amanda.corley@health.qld.gov.au

- Additional material is published online only. To view please visit the journal online (http://dx.doi.org/10. 1136/thoraxjnl-2015-207962).

Acknowledgements The authors would like to acknowledge the Respiratory Physicians for their support and Lisa McCarthy for her encouragement and assistance throughout the project. 
Contributors JFF contributed to study design, manuscript preparation, data interpretation and manuscript review. KRD, AJS and AC contributed to study design, data collection, cleaning and interpretation, manuscript preparation and manuscript review. CMA contributed to data cleaning, analysis and interpretation, manuscript preparation and manuscript review.

Competing interests JFF has received a research fellowship from Queensland Health Office of Health and Medical Research. JFF received an unrestricted grant from Fisher \& Paykel Healthcare in support of the current study. JFF and AC have received assistance from Fisher \& Paykel Healthcare to support travel and accommodation costs to attend research meetings; neither has received honoraria or consultancy fees from Fisher \& Paykel;

Patient consent Obtained.

Ethics approval Institutional Human Research and Ethics Committee (HREC/11/QPCH/152).

Provenance and peer review Not commissioned; externally peer reviewed.

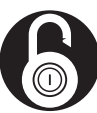

\section{OPEN ACCESS}

Open Access This is an Open Access article distributed in accordance with the Creative Commons
Attribution Non Commercial (CC BY-NC 4.0) license, which permits others to distribute, remix, adapt, build upon this work non-commercially, and license their derivative works on different terms, provided the original work is properly cited and the use is noncommercial. See: http://creativecommons.org/licenses/ by-nc/4.0/

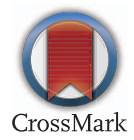

To cite Fraser JF, Spooner AJ, Dunster K R, et al. Thorax 2016;71:759-761.

Received 18 October 2015

Revised 22 February 2016

Accepted 26 February 2016

Published Online First 25 March 2016

Thorax 2016;71:759-761.

doi:10.1136/thoraxjnl-2015-207962

\section{REFERENCES}

1 Kent BD, Mitchell PD, McNicholas WT. Hypoxemia in patients with COPD: cause, effects, and disease progression. Int I Chron Obstruct Pulmon Dis 2011;6:199-208

2 Parke RL, McGuinness SP. Pressures delivered by nasal high flow oxygen during all phases of the respiratory cycle. Respir Care 2013;58:1621-4.

3 Corley A, Caruana LR, Barnett AG, et al. Oxygen delivery through high-flow nasal cannulae increase end-expiratory lung volume and reduce respiratory rate in post-cardiac surgical patients. $\mathrm{Br} J$ Anaesth 2011;107:998-1004.

4 Dysart K, Miller TL, Wolfson MR, et al. Research in high flow therapy: mechanisms of action. Respir Med 2009;103:1400-5.

5 Chatila W, Nugent T, Vance G, et al. The effects of high-flow vs low-flow oxygen on exercise in advanced obstructive airways disease. Chest 2004;126:1108-15.

6 Okuda M, Kashio M, Tanaka N, et al. Nasal high-flow oxygen therapy system for improving sleep-related hypoventilation in chronic obstructive pulmonary disease: a case report. I Med Case Rep 2014;8:341.

7 Bräunlich J, Beyer D, Mai D, et al. Effects of nasal high flow on ventilation in volunteers, COPD and idiopathic pulmonary fibrosis patients. Respiration 2013:85:319-25.

8 Stéphan F, Barrucand B, Petit P, et al. High-flow nasal oxygen vs noninvasive positive airway pressure in hypoxemic patients after cardiothoracic surgery. A randomized clinical trial. JAMA 2015;313:2331-9.

9 Frat JP, Thille AW, Mercat A, et al. High-flow oxygen through nasal cannula in acute hypoxemic respiratory failure. N Engl I Med 2015;372:2185-96.

10 Rea H, McAuley S, Jayaram L, et al. The clinical utility of long-term humidification therapy in chronic airways disease. Respir Med 2010;104:525-33. 